\title{
Avaliação de diferentes inclinações e exposições de telhado em três tipos de cobertura em modelos reduzidos de instalações zootécnicas
}

\section{Evaluation of different roof slopes and exposure in three types of coverage in models of animal installations}

\author{
Thiago Melo ${ }^{1 *}$; Renato Furlan²; Adhemar Milani; \\ Marcos Buzanskas ${ }^{4}$; Adolpho Moura ${ }^{5}$; Diego Mota ${ }^{6}$; Diercles Cardoso ${ }^{7}$
}

\begin{abstract}
Resumo
O presente trabalho foi desenvolvido junto aos Departamentos de Engenharia Rural e Morfologia e Fisiologia Animal da FCAV/Unesp. Objetivou-se verificar a influencia da inclinação e exposição norte e sul com a telha de cerâmica, aço galvanizado e fibrocimento em modelos reduzidos de instalações zootécnicas. Foram utilizados 48 modelos reduzidos nas dimensões de 1,00 x 1,00 x 0,50 metros. A cobertura foi de uma água, dispostos nas exposições Norte-Sul, laterais e piso de compensado de madeira, sendo 24 modelos na exposição norte e 24 na sul. Foram utilizadas na cobertura, telha de cerâmica, aço galvanizado e fibrocimento. As inclinações variaram de 20,30, 40 e 50\% para telha de cerâmica e 10, 30, 40 e 50\% para as demais. No interior dos modelos foram realizadas leituras de temperatura, de hora em hora durante um ano, pelo sistema de aquisição de dados Marca Campbell Scientific-Ínc. Externamente foram medidas e registradas a temperatura do ar, radiação solar global incidente, precipitação, velocidade e umidade relativa do ar pela estação meteorológica do departamento de Ciências Exatas da FCAV/Unesp. Os resultados obtidos foram avaliados num modelo linear geral no esquema fatorial aninhado $3 \mathrm{X} 4 \mathrm{X} 2$, em que foram considerados: tipo de telha, grau de inclinação e exposição, onde os efeitos de cobertura e exposição foram aninhados no fator inclinação. As médias obtidas foram comparadas pelo teste de Tukey a $5 \%$ de probabilidade. Observou-se que com o aumento da inclinação na exposição sul, houve decréscimo das variáveis analisadas no interior dos modelos nas coordenadas geográficas da cidade de Jaboticabal.
\end{abstract}

Palavras-chave: Ambiência, avicultura, galpão, temperatura

\begin{abstract}
The present study was developed in Departamentos de Engenharia Rural e Morfologia e Fisiologia Animal da FCAV/Unesp. The objective of evaluating different roof slopes and exposure in three types of coverage in models of animal installations. Project 48 built reduced models of wood were used with dimensions of $1,00 \times 1,00 \times 0,50$ meters. The covering was one water, lateral and wood floor, disposed
\end{abstract}

\footnotetext{
${ }^{1}$ Prof. do Dept ${ }^{\circ}$ de Zootecnia da Universidade Federal dos Vale de Jequitinhonha e Mucuri, UFVJM, Diamantina, MG. E-mail: thiagovmelo@gmail.com

2 Prof. do Dept ${ }^{\circ}$ de Morfologia e Fisiologia Animal da Universidade Estadual Paulista "Júlio de Mesquita Filho", UNESP, Jaboticabal, SP. E-mail: rlfurlan@fcav.unesp.br

${ }^{3}$ Prof. do Dept ${ }^{\circ}$ de Engenharia Rural, UNESP, Jaboticabal, SP. E-mail: apmilani@fcav.unesp.br

${ }^{4}$ Discente de Doutorado em Melhoramento Genético, UNESP, Jaboticabal, SP. E-mail: marcosbuz@yahoo.com.br

${ }^{5}$ Pesquisador do Centro de Pesquisas Aggeu Magalhães da Fundação Oswaldo Cruz Recife, PE. E-mail: antoniol@cpqam.fiocruz. br

${ }^{6}$ Prof. do Instituto de Biodiversidade e Florestas da Universidade Federal do Oeste do Pará, UFOPA, Santarém, PA. E-mail: diegomota@zootecnista.com.br

${ }^{7}$ Discente de Mestrado em Melhoramento Genético, UNESP, Jaboticabal, SP. E-mail: diercles.cardoso@yahoo.com.br

* Autor para correspondência
} 
in the exhibitions North-south, being 24 prototypes in the north exhibition and 24 in the south. Were used in the covering roofs of ceramic type, galvanized steel and asbestos. The slopes varied of 20, 30, 40 and $50 \%$ for ceramic tile and $10,30,40$ and $50 \%$ for the others and with two repetitions for slope. Inside the reduced models temperature readings were accomplished, of hour in hour during one year, for the system of acquisition of Data Logger Campbell Scientific-Ínc and externally the temperature of the air, incident radiation global solar, precipitation, speed and relative humidity of the air were measured. The results obtained during the experimental period of one year were appraised statistically for the statistical package SAS in the factorial outline, where three factors were considered: tile type, slope degree and exposure. The obtained averages were compared through the test of Tukey to $5 \%$ of probability. After analyzing the data we found that with increasing slope, there was a decrease in inside temperature in the cover prototypes, therefore, using steeper slopes with $50 \%$ of tipping ceramics and asbestos, with greater coverage on display South, we have lower temperatures in poultry houses in the geographic coordinates of the city of Jaboticabal.

Key words: Poultry house, temperature, environment, poultry

\section{Introdução}

A agropecuária brasileira tem se destacado pelo seu alto nível tecnológico, com importante progresso científico, resultado especialmente de contribuições de pesquisas nas áreas de genética, nutrição, manejo e sanidade. No entanto, o alto grau de confinamento, associado aos elevados índices de desempenho, trouxe maior vulnerabilidade desses animais a elementos do ambiente. Dessa forma, torna-se inadmissível, na Zootecnia moderna, negligenciar os aspectos relativos ao ambiente térmico, uma vez que condições que se afastam do conforto térmico, causado principalmente pelas altas temperaturas, provocam maiores desperdícios de energia produtiva. Algumas conseqüências desse quadro têm sido problemas cardíacos e pulmonares (MATIAS; PATARRA, 1995), os quais podem, no entanto, ser amenizados, desde que as aves sejam criadas em condições ambientais apropriadas (SARTOR et al., 2001).

Aproximadamente $60 \%$ da produção de frango de corte no Brasil estão sujeito a condições adversas de temperatura, ou seja, desconforto térmico, especialmente em regiões que concentram altas temperaturas ao longo do ano (NÄÄS et al., 2010), causando prejuízos econômicos, e diminuindo a qualidade da carne, prejudicando o rendimento de cortes nobres de frangos com idade entre 1 a 49 dias (OLIVEIRA et al., 2006).
Grande parte da produção brasileira encontrase em condições desfavoráveis em relação ao bem estar animal, corroborando com Silva, Naas e Moura (2009) que observaram a necessidade de investir em melhora nas normas e legislações de bem-estar animal no país. Contudo, ainda há muita carência de investigações acerca do bem-estar para as condições arquitetônicas e construtivas dos galpões avícolas brasileiros (CORDEIRO et al., 2010). O desenvolvimento de pesquisas em instalações zootécnicas em escala natural é muito oneroso se tornando inviável, portanto o uso de modelos reduzidos tem sido uma boa solução para resolver esses problemas sendo uma ferramenta largamente utilizada na engenharia. Pesquisadores como Hann, Bond e Kelly (1961), Forehlich, Hellickson e Young (1975), Bottcher, Willits e Baughman (1986), Celis e Jara (1990), utilizaram modelos em escala distorcida em seus experimentos envolvidos na área em questão. Além de reproduzirem as características e respostas térmicas de instalações naturais, esses modelos reduzem os custos e o tempo de experimentação.

A observação quantitativa da radiação solar que incide sobre as superfícies inclinadas em relação à superfície horizontal, com diferentes ângulos de inclinação, é utilizada em grande variedade de aplicações, incluindo projetos de engenharia para coletores solares, projetos de arquitetura, planejamento urbano, estudos agronômicos 
de insolação sobre a vegetação e em estudos micrometeorológicos sobre circulação local. O objetivo deste trabalho foi verificar a influencia da inclinação e exposição norte e sul em telhas de fibrocimento sobre o calor retido, na variação de temperatura externa e interna e entalpia no interior de modelos reduzidos de instalações zootécnicas.

\section{Material e Métodos}

O experimento foi conduzido na Faculdade de Ciências Agrárias e Veterinárias- FCAV/Unesp, Jaboticabal, SP junto aos Departamentos de Engenharia Rural e o Departamento de Morfologia e Fisiologia Animal. Foram construídos 48 modelos reduzidos com dimensões de $1,00 \times 1,00$ x 0,50 $\mathrm{m}$, apresentando assim o mesmo volume de ar no interior de todos os modelos. Foram construídos hastes de madeira com diferentes tamanhos para inclinar os mesmos, com o intuito de inclinar as coberturas. Os modelos foram construídos dentro do Campus da Unesp Jaboticabal, localizado a uma latitude de $21^{\circ} 14$ minutos 05 segundos $\mathrm{S}$, longitude $48^{\circ} 17$ minutos 09 segundos $\mathrm{W}$ e altitude de 615,01 metros., utilizando uma área de $160 \mathrm{~m}^{2}$.

O material utilizado foi o compensado de madeira com 6,0 $\mathrm{mm}$ de espessura nas laterais e no piso com o objetivo de evitar ao máximo o efeito das variáveis climáticas do exterior, para que as alterações do ambiente interno sejam, em sua maior parte, devido os efeitos provenientes da cobertura. Os modelos reduzidos fabricados com compensados foram pintados com tinta branca impermeabilizante para, além de aumentar sua refletividade, aumentar também sua resistência contra as intempéries. As coberturas foram de 1 água, com os modelos posicionados na orientação leste-oeste, e as coberturas dos modelos dispostas para Norte-Sul, sendo 24 modelos na exposição norte e 24 na sul, e com duas repetições por inclinação. Os modelos foram cobertos com telha de cerâmica tipo romana, aço galvanizado $0,50 \mathrm{~mm}$ e fibrocimento $6,0 \mathrm{~mm}$ de espessura. As inclinações dos telhados foram de
20, 30, 40 e 50\% para telha de cerâmica e 10, 30, 40 e $50 \%$ para as demais. Na cobertura de cerâmica não foi utilizada a inclinação de $10 \%$ devido às especificações técnicas de engenharia, telhas de cerâmica não podem ser instaladas com inclinações menores de $20 \%$.

Foram avaliadas as telhas de cerâmica, aço galvanizado e fibrocimento em diferentes inclinações de telhado e sua exposição quanto a influencia no calor retido, na variação de temperatura externa e interna e entalpia no interior dos modelos. Os dados do ambiente externo durante o período experimental foram colhidos pelo Departamento de Ciências Exatas da UNESP/Jaboticabal, pela estação meteorológica automática e convencional. Para a obtenção dos dados de temperatura interna dos modelos foram utilizados dois termopares tipo $\mathrm{T}$, modelo $105 \mathrm{~T}$, com acurácia de $\pm 1^{\circ} \mathrm{C}$, devidamente posicionados um no centro do modelo e o segundo a dois centímetros abaixo da cobertura, através de suportes de madeira. A leitura dos dados de temperatura interna dos modelos foi realizada de hora em hora durante um ano, por meio do sistema de aquisição de dados, Datalogger marca CAMPBELL SCIENTIFIC-INC. Depois de colhidos os dados foram selecionados os dias que possuíam razão de insolação acima de $85 \%$ (obtida na estação meteorológica do Departamento de Ciências Exatas da UNESP/Jaboticabal) para evitar dias sombreados e chuvosos. Para análise dos dados, foram utilizadas as temperaturas dos horários de 12:00 as 14:00, para maximizar o efeito da temperatura sobre o modelo, separados entre as estações verão, primavera, outono e inverno. Os dados de radiação solar estimada foram colhidos pela Estação Meteorológica do Departamento de Engenharia Rural da FCAV/ UNESP em uma estrutura denominada "Bacia Hidrográfica Experimental”, descrita com detalhes por Turco (1997), em que foram utilizados os dias filtrados com razão de insolação acima de $85 \%$ e separados entre as estações primavera, verão, outono e inverno. As variáveis analisadas foram: calor retido, a variação de temperatura externa e interna do modelo $(\Delta \mathrm{t})$ e a entalpia. 
A quantidade de calor retido e perdido estimado dentro do modelo foi calculada utilizando a seguinte equação:

$$
\mathrm{Q}=\mathrm{m} \cdot \mathrm{c} \cdot \Delta \mathrm{t}
$$

Em que:

$\mathrm{Q}=$ Calor retido/perdido;

$\mathrm{m}=$ massa;

$\mathrm{c}=$ calor específico (cal);

$\Delta \mathrm{t}=$ variação de temperatura.

$\mathrm{O}$ volume do modelo foi igual a $0,5 \mathrm{~m}^{3}$, tendo como massa $600 \mathrm{~g}$, o calor específico do ar é igual a $0,24 \mathrm{cal} / \mathrm{g} .{ }^{\circ} \mathrm{C}$ e para os dados de variação de temperatura no interior do modelo foram utilizados os valores de temperatura obtidos entre as 6:00 e 14:00 h. Para o cálculo de variação de temperatura externa e interna do modelo $(\Delta \mathrm{t})$, foram utilizados as temperaturas máximas do interior do modelo menos a temperatura máxima externa.

Para o cálculo de entalpia, foi utilizado o programa computacional da Universidade Federal de Viçosa GRAPSI 6.0®, que considera a temperatura de bulbo seco, umidade relativa e a pressão atmosférica local para estimar o valor de entalpia. Esta, por definição, é a energia do ar úmido por unidade de massa de ar seco (kJ/kg de ar seco), ou seja, é uma variável física que indica a quantidade de energia contida em uma mistura de vapor d'água. Os resultados obtidos foram analisados em um modelo linear geral pelo pacote estatístico SAS 9.1 software (SAS Institute, Cary, NC, USA, 2004) no esquema fatorial aninhado $3 \mathrm{X} 4 \mathrm{X} 2$, para os valores considerados: tipo de telha, grau de inclinação e exposição, os efeitos de cobertura e exposição foram aninhados no fator inclinação. As médias obtidas foram comparadas por intermédio do teste de Tukey a $5 \%$ de probabilidade, seguindo-se o modelo estatístico a seguir:

$$
Y i j k l=m+C i+E j+C E(i j)+I k:(C i E j)+e i j k l
$$

Em que:

Yijkl = Observação da cobertura i, com a inclinação $\mathrm{j}$ e exposição $\mathrm{k}$

$\mathrm{m}=$ Média geral;

$\mathrm{Ci}=$ efeito do tipo i de material de cobertura, em que $\mathrm{i}=1,2,3$;

$E j=$ efeito da exposição $j$, em que $j=1,2$;

$\mathrm{CE}(\mathrm{ik})=$ efeito da interação entre tipo $\mathrm{i}$ de material de cobertura e exposição j;

Ik : $(\mathrm{CiEj})=$ efeitos da interação inclinação $\mathrm{k}$ aninhado entre tipo i de material de

cobertura e exposição j;

e ijk = erro associado a cada observação.

\section{Resultados e Discussão}

De acordo com os resultados podemos observar que ao aumentar a inclinação da cobertura na exposição sul, foi observado decréscimo de radiação solar global incidente. Isto se deve à menor incidência de radiação solar global estimada em superfícies com maior inclinação na exposição sul como representado na Tabela 1 , em que estão apresentados os dados de radiação solar global estimada nas diferentes inclinações e exposições nas estações primavera, verão, outono e inverno. Demonstrando que a incidência de radiação solar incidente em Jaboticabal na exposição norte é muito maior, principalmente no inverno. Este fato pode ser de muita importância se o interesse é ter uma instalação para pintinhos ou leitegadas, ou ainda em regiões nas quais as médias de temperatura são muito baixas, como em certas regiões do sul do Brasil. 
Tabela 1. Radiação solar global estimada para diferentes inclinações e sentido de exposição do telhado nas diferentes estações do ano.

\begin{tabular}{|c|c|c|c|c|c|c|c|c|c|c|}
\hline \multicolumn{11}{|c|}{ Radiação Estimada cal $/ \mathrm{cm}^{2} /$ dia } \\
\hline & $10 \mathrm{~N}$ & $10 \mathrm{~S}$ & $20 \mathrm{~N}$ & $20 \mathrm{~S}$ & $30 \mathrm{~N}$ & $30 \mathrm{~S}$ & $40 \mathrm{~N}$ & $40 \mathrm{~S}$ & $50 \mathrm{~N}$ & $50 \mathrm{~S}$ \\
\hline Verão & 634,5 & 630,7 & 627,2 & 619,7 & 614,8 & 603,5 & 598,1 & 583,2 & 578,3 & 560,2 \\
\hline Primavera & 449,9 & 454,9 & 440,9 & 450,8 & 428,5 & 442,8 & 413,2 & 431,5 & 396,2 & 418,0 \\
\hline Outono & 503,8 & 413,8 & 541,3 & 365,2 & 572,5 & 315,9 & 597,4 & 267,6 & 616,3 & 221,5 \\
\hline Inverno & 495,9 & 422,8 & 524,8 & 380,9 & 547,8 & 337,4 & 565,2 & 293,9 & 577,3 & 251,6 \\
\hline
\end{tabular}

Fonte: Elaboração dos autores.

Na tabela 2 apenas no outono houve interação significativa na cobertura e exposição, aninhados com o fator inclinação sobre o calor retido estimado. Percebe-se que para a cobertura de fibrocimento e cerâmica a inclinação de $50 \%$ exposição sul foi a que obteve melhor eficiência térmica (menores valores de calor retido estimado), porém esta diferença estatística não foi observada para a cobertura de aço galvanizado nas inclinações na exposição norte e sul. Ao aumentar a inclinação do telhado, modificase a altura entre as aberturas de entrada e saída de ar afetando o condicionamento térmico ambiental no interior do galpão, mudando o coeficiente de forma correspondente às trocas de calor por radiação entre o animal e o telhado. Resultados de melhora nos índices de conforto térmico no interior de galpões ao se aumentar a inclinação também foram observados por Tinôco (2001).
Nas demais estações (verão, primavera e inverno) não houve interação entre exposição aninhados com o fator inclinação sobre o Q cal (Tabela 3). No entanto ocorreram diferenças significativas (Tabela 4), no qual a exposição sul reteve menos calor, pois a quantidade total de radiação recebida numa superfície varia de acordo com a exposição e a declividade (COAN, 2008). Sendo assim, os menores valores de calor retido estimado na exposição sul se deve a menor intensidade da radiação solar que incide sobre esta exposição nas coordenadas geográficas de Jaboticabal associada à telha de cerâmica com o menor índice de retenção de calor. Segundo Almeida et al. (1997), a quantidade de calor armazenado por um dado elemento construtivo depende de vários fatores, como as propriedades termofísicas dos materiais que os constituem, a área e a espessura, a distribuição interna das temperaturas, a evolução das temperaturas ambientes dos dois lados do elemento armazenador, a localização desse, e ainda, se esse elemento está ou não sob a ação direta da radiação solar. 
Tabela 2. Médias estimadas da interação entre cobertura e exposição aninhados com o fator inclinação sobre o calor retido (Q cal) em todas as estações.

\begin{tabular}{|c|c|c|c|c|c|c|}
\hline \multicolumn{7}{|c|}{ Verão } \\
\hline & \multicolumn{2}{|c|}{ Cerâmica } & \multicolumn{2}{|c|}{ Fibrocimento } & \multicolumn{2}{|c|}{ Aço Galvanizado } \\
\hline & Norte & Sul & Norte & Sul & Norte & Sul \\
\hline $10 \%$ & - & - & 2,44 & 2,48 & 2,52 & 2,52 \\
\hline $20 \%$ & 2,30 & 2,44 & - & - & - & - \\
\hline $30 \%$ & 2,39 & 2,46 & 2,43 & 2,41 & 2,51 & 2,50 \\
\hline $40 \%$ & 2,41 & 2,36 & 2,43 & 2,40 & 2,63 & 2,57 \\
\hline $50 \%$ & 2,46 & 2,13 & 2,39 & 2,34 & 2,78 & 2,71 \\
\hline \multicolumn{7}{|c|}{ Primavera } \\
\hline & \multicolumn{2}{|c|}{ Cerâmica } & \multicolumn{2}{|c|}{ Fibrocimento } & \multicolumn{2}{|c|}{ Aço Galvanizado } \\
\hline & Norte & Sul & Norte & Sul & Norte & Sul \\
\hline $10 \%$ & - & - & 2,82 & 2,80 & 2,89 & 2,85 \\
\hline $20 \%$ & 2,75 & 2,76 & - & - & - & - \\
\hline $30 \%$ & 2,80 & 2,77 & 2,77 & 2,69 & 2,85 & 2,85 \\
\hline $40 \%$ & 2,87 & 2,65 & 2,87 & 2,71 & 2,96 & 2,89 \\
\hline $50 \%$ & 2,89 & 2,46 & 2,77 & 2,59 & 3,05 & 2,94 \\
\hline \multicolumn{7}{|c|}{ Outono } \\
\hline & \multicolumn{2}{|c|}{ Cerâmica } & \multicolumn{2}{|c|}{ Fibrocimento } & \multicolumn{2}{|c|}{ Aço Galvanizado } \\
\hline & Norte & Sul & Norte & Sul & Norte & Sul \\
\hline $10 \%$ & - & - & $2,34 \mathrm{aA}$ & $2,35 \mathrm{aA}$ & $2,48 \mathrm{aA}$ & $2,50 \mathrm{aA}$ \\
\hline $20 \%$ & $2,45 \mathrm{aA}$ & $2,48 \mathrm{aA}$ & - & - & - & - \\
\hline $30 \%$ & $2,50 \mathrm{aA}$ & $2,44 \mathrm{abA}$ & $2,35 \mathrm{abA}$ & $2,26 \mathrm{bAB}$ & $2,52 \mathrm{aA}$ & $2,51 \mathrm{aA}$ \\
\hline $40 \%$ & $2,44 \mathrm{abA}$ & $2,29 \mathrm{abAB}$ & $2,31 \mathrm{abA}$ & $2,24 \mathrm{bAB}$ & $2,52 \mathrm{aA}$ & $2,47 \mathrm{abA}$ \\
\hline $50 \%$ & $2,45 \mathrm{abA}$ & $2,10 \mathrm{cB}$ & $2,31 \mathrm{bcA}$ & $2,13 \mathrm{cB}$ & $2,64 \mathrm{aA}$ & $2,49 \mathrm{abA}$ \\
\hline \multicolumn{7}{|c|}{ Inverno } \\
\hline & \multicolumn{2}{|c|}{ Cerâmica } & \multicolumn{2}{|c|}{ Fibrocimento } & \multicolumn{2}{|c|}{ Aço Galvanizado } \\
\hline & Norte & Sul & Norte & Sul & Norte & Sul \\
\hline $10 \%$ & - & - & 2,53 & 2,54 & 2,63 & 2,62 \\
\hline $20 \%$ & 2,50 & 2,56 & - & - & - & - \\
\hline $30 \%$ & 2,56 & 2,55 & 2,51 & 2,45 & 2,63 & 2,62 \\
\hline $40 \%$ & 2,58 & 2,43 & 2,53 & 2,45 & 2,70 & 2,64 \\
\hline $50 \%$ & 2,60 & 2,23 & 2,49 & 2,35 & 2,82 & 2,72 \\
\hline
\end{tabular}

* As médias seguidas pela mesma letra dentro das estações não diferem estatisticamente entre si pelo teste de Tukey a $5 \%$.Letras minúsculas para linhas e maiúsculas para colunas.

Fonte: Elaboração dos autores. 
Tabela 3. Média estimada do calor retido (Q cal) dos modelos com cobertura de cerâmica, fibrocimento e aço galvanizado durante o verão, primavera e inverno.

\begin{tabular}{ccc}
\hline & Verão & \\
\hline Cerâmica & Fibrocimento & Aço Galvanizado \\
$2,37 \mathrm{~b}$ & $2,41 \mathrm{~b}$ & $2,59 \mathrm{a}$ \\
\hline & Primavera & \\
\hline Cerâmica & Fibrocimento & Aço Galvanizado \\
$2,74 \mathrm{~b}$ & $2,75 \mathrm{~b}$ & $2,91 \mathrm{a}$ \\
\hline & Inverno & \\
\hline Cerâmica & Fibrocimento & Aço Galvanizado \\
$2,50 \mathrm{~b}$ & $2,48 \mathrm{~b}$ & 2,67 a \\
\hline
\end{tabular}

* As médias seguidas pela mesma letra dentro das estações não diferem estatisticamente entre si pelo teste de Tukey a 5\%

Fonte: Elaboração dos autores.

Tabela 4. Média estimada do calor retido (Q cal) dos modelos com cobertura de cerâmica, fibrocimento e aço galvanizado durante a primavera exposições norte e sul.

\begin{tabular}{cc}
\hline & Primavera \\
\hline Exposição Norte & Exposição Sul \\
$2,85 \mathrm{a}$ & $2,74 \mathrm{~b}$ \\
\hline
\end{tabular}

* As médias seguidas pela mesma letra não diferem estatisticamente entre si pelo teste de Tukey a 5\%

Fonte: Elaboração dos autores.

Nos resultados de $\Delta \mathrm{t}^{\circ} \mathrm{C}$ (Tabela 5), as inclinações de $50 \%$ com cobertura de cerâmica na exposição sul foi menor que as inclinações de 20 e $30 \%$ com cobertura de cerâmica na exposição sul e a cobertura de fibrocimento com $50 \%$ de inclinação também diferiu estatisticamente $(\mathrm{p}<0,05)$ da inclinação de $10 \%$ exposição sul ambas na estação do outono. Porém ao analisarmos as estações mais quentes do ano (primavera e verão), não observamos nenhuma diferença significativa entre os valores.

Os resultados obtidos diferem das conclusões de melhor desempenho de telhas cerâmicas observadas por Parker (1963); Sevegnani, Ghelfi Filho e Silva (1994); Jácome et al. (2007); Furtado, Azevedo e Tinoco (2003); Santos, Yanagi Junior e Teixeira (2005). Provavelmente, o modelo utilizado não conseguiu captar esta diferença observada pelos autores mencionados, já que se era esperado o melhor desempenho da telha de cerâmica, pois às propriedades térmicas e mecânicas desta telha são melhores do que das telhas de fibrocimento e aço galvanizado. Pode-se observar na Tabela 6, que apesar de apresentar diferenças significativas entre as coberturas e a estação do ano, a telha de cerâmica não diferiu estatisticamente da telha de fibrocimento, corroborando com o fato do modelo não ter sido capaz de captar diferenças de temperatura mais sutis.

$\mathrm{Na}$ Tabela 7, observamos que na primavera e no inverno, ocorreram diferenças significativas $(p<0,05)$ entre as exposições, como observado anteriormente nos resultados de radiação solar global estimada. 
Tabela 5. Médias da interação entre cobertura e exposição aninhados com o fator inclinação sobre variação de temperatura máxima interna ${ }^{\circ} \mathrm{C}$ - temperatura máxima externa ${ }^{\circ} \mathrm{C}\left(\Delta \mathrm{t}^{\circ} \mathrm{C}\right)$ em todas as estações.

\begin{tabular}{|c|c|c|c|c|c|c|}
\hline \multicolumn{7}{|c|}{ Verão } \\
\hline & \multicolumn{2}{|c|}{ Cerâmica } & \multicolumn{2}{|c|}{ Fibrocimento } & \multicolumn{2}{|c|}{ Aço Galvanizado } \\
\hline & Norte & Sul & Norte & Sul & Norte & Sul \\
\hline $10 \%$ & - & - & 4,1 & 4,6 & 4,8 & 4,9 \\
\hline $20 \%$ & 3,0 & 4,0 & - & - & - & - \\
\hline $30 \%$ & 3,6 & 4,1 & 3,9 & 3,9 & 4,7 & 4,7 \\
\hline $40 \%$ & 3,9 & 3,5 & 4,0 & 3,9 & 5,6 & 5,2 \\
\hline $50 \%$ & 4,3 & 1,8 & 3,7 & 3,4 & 6,7 & 6,4 \\
\hline \multicolumn{7}{|c|}{ Primavera } \\
\hline & \multicolumn{2}{|c|}{ Cerâmica } & \multicolumn{2}{|c|}{ Fibrocimento } & \multicolumn{2}{|c|}{ Aço Galvanizado } \\
\hline & Norte & Sul & Norte & Sul & Norte & Sul \\
\hline $10 \%$ & - & - & 4,1 & 4,0 & 4,8 & 4,6 \\
\hline $20 \%$ & 3,4 & 3,5 & - & - & - & - \\
\hline $30 \%$ & 3,9 & 3,5 & 3,6 & 3,2 & 4,4 & 4,6 \\
\hline $40 \%$ & 4,4 & 2,9 & 4,5 & 3,4 & 5,3 & 4,9 \\
\hline $50 \%$ & 4,7 & 1,5 & 3,7 & 2,5 & 6,1 & 5,5 \\
\hline \multicolumn{7}{|c|}{ Outono } \\
\hline & \multicolumn{2}{|c|}{ Cerâmica } & \multicolumn{2}{|c|}{ Fibrocimento } & \multicolumn{2}{|c|}{ Aço Galvanizado } \\
\hline & Norte & Sul & Norte & Sul & Norte & Sul \\
\hline $10 \%$ & - & - & $4,5 \mathrm{aA}$ & $4,7 \mathrm{aA}$ & $5,7 \mathrm{aA}$ & $6,1 \mathrm{aA}$ \\
\hline $20 \%$ & $5,4 \mathrm{aA}$ & $5,7 \mathrm{aA}$ & - & - & - & - \\
\hline $30 \%$ & 5,9abA & $5,2 \mathrm{abcA}$ & $4,6 \mathrm{bcA}$ & $3,9 \mathrm{cAB}$ & $6,1 \mathrm{aA}$ & $6,1 \mathrm{aA}$ \\
\hline $40 \%$ & $5,4 \mathrm{abA}$ & $4,4 \mathrm{abAB}$ & $4,2 \mathrm{abA}$ & $3,9 \mathrm{bAB}$ & $6,0 \mathrm{aA}$ & $5,8 \mathrm{aA}$ \\
\hline $50 \%$ & 5,5abA & $2,9 \mathrm{cB}$ & $4,2 \mathrm{bcA}$ & $3,0 \mathrm{cB}$ & $7,0 \mathrm{aA}$ & $5,9 \mathrm{abA}$ \\
\hline \multicolumn{7}{|c|}{ Inverno } \\
\hline & \multicolumn{2}{|c|}{ Cerâmica } & \multicolumn{2}{|c|}{ Fibrocimento } & \multicolumn{2}{|c|}{ Aço Galvanizado } \\
\hline & Norte & Sul & Norte & Sul & Norte & Sul \\
\hline $10 \%$ & - & - & 7,8 & 8,0 & 8,7 & 8,8 \\
\hline $20 \%$ & 7,6 & 8,0 & - & - & - & - \\
\hline $30 \%$ & 8,1 & 7,9 & 7,6 & 7,3 & 8,7 & 8,7 \\
\hline $40 \%$ & 8,2 & 7,2 & 7,8 & 7,3 & 9,2 & 8,9 \\
\hline $50 \%$ & 8,5 & 5,6 & 7,5 & 6,6 & 10,2 & 9,5 \\
\hline
\end{tabular}

* As médias seguidas pela mesma letra dentro das estações não diferem estatisticamente entre si pelo teste de Tukey a 5\% . Letras minúsculas para linhas e maiúsculas para colunas.

Fonte: Elaboração dos autores. 
Tabela 6. Médias da temperatura máxima interna ${ }^{\circ} \mathrm{C}$ - temperatura máxima externa ${ }^{\circ} \mathrm{C}\left(\Delta \mathrm{t}^{\circ} \mathrm{C}\right)$ dos modelos com cobertura de cerâmica, fibrocimento e aço galvanizado durante o verão, primavera e inverno.

\begin{tabular}{ccc}
\hline & Verão & \\
\hline Cerâmica & Fibrocimento & Aço Galvanizado \\
$3,57 \mathrm{~b}$ & $3,96 \mathrm{~b}$ & $5,41 \mathrm{a}$ \\
\hline & Primavera & \\
\hline Cerâmica & Fibrocimento & Aço Galvanizado \\
$3,52 \mathrm{~b}$ & $3,65 \mathrm{~b}$ & $5,05 \mathrm{a}$ \\
\hline & Inverno & \\
\hline Cerâmica & Fibrocimento & Aço Galvanizado \\
$7,67 \mathrm{~b}$ & $7,54 \mathrm{~b}$ & 9,12 a \\
\hline
\end{tabular}

* As médias seguidas pela mesma letra dentro das estações não diferem estatisticamente entre si pelo teste de Tukey a 5\%

Fonte: Elaboração dos autores.

Tabela 7. Médias da temperatura máxima interna ${ }^{\circ} \mathrm{C}$ - temperatura máxima externa ${ }^{\circ} \mathrm{C}\left(\Delta \mathrm{t}^{\circ} \mathrm{C}\right)$ dos modelos com cobertura de cerâmica, fibrocimento e aço galvanizado durante a primavera e inverno nas exposições Norte e Sul.

\begin{tabular}{ccc}
\hline & Primavera & \\
\hline Exposição Norte & & Exposição Sul \\
$4,44 \mathrm{a}$ & & $3,71 \mathrm{~b}$ \\
\hline & Inverno & \\
\hline Exposição Norte & Exposição Sul \\
$8,36 \mathrm{a}$ & $7,85 \mathrm{~b}$ \\
\hline
\end{tabular}

* As médias seguidas pela mesma letra dentro das estações não diferem estatisticamente entre si pelo teste de Tukey a 5\% Fonte: Elaboração dos autores.

Ao analisar separadamente o desempenho térmico da cobertura de aço galvanizado, os resultados devem-se provavelmente a maior condutividade dos materiais metálicos, ou seja, os metais possuem uma maior capacidade de receber calor ou frio, mas também possuem uma maior facilidade em dispersálos, assim sendo, aqueceriam mais rapidamente que os outros materiais e esfriariam mais rápido consequentemente. Quanto mais isolante for $\mathrm{o}$ material, menor é o coeficiente de condutibilidade térmica, sendo este de $39,4 \mathrm{~W} / \mathrm{m}^{\circ} \mathrm{K}$ para a telha de aço galvanizado e 0,48 e $1,15 \mathrm{~W} / \mathrm{m}^{\circ} \mathrm{K}$ para telha de fibrocimento e cerâmica respectivamente.

Segundo Oliveira et al. (2009), superfícies com elevada refletância permanecem mais frias quando expostas a radiação solar, pois absorvem menos radiação e emitem mais radiação térmica para o espaço, consequentemente, transmitem menos calor para seu entorno, porém a telha metálica foi a que apresentou em seu estudo o pior desempenho térmico, mesmo tendo maior taxa de refletância, o que pode ser explicado pela baixa emissividade do material, tornando seu ambiente interno mais desconfortável.

No entanto, não se notou esta maior capacidade em dispersar o calor retido durante o dia. Pode ser que a capacidade de dispersar o calor retido mais rapidamente não tenha sido captada na coleta dos dados, ou pela baixa renovação de ar no interior do modelo possa ter influenciado o resultado negativo da telha de aço galvanizado. Segundo Parker (1963) e Sevegnani, Ghelfi Filho e Silva (1994) apresentaram bons desempenhos deste tipo de telha, no entanto Oliveira et al. (2009) observaram um pior comportamento da telha de aço galvanizada, concluindo que este pior desempenho era devido a sua uma baixa emissividade. 
Com os resultados deste trabalho, há evidencias de que com a mudança de inclinação e exposição, podemos ter no final de um ano, uma economia de energia na utilização de ventiladores, nebulizadores e consequentemente um maior desempenho em prol de um maior conforto térmico, pois diminuiremos a temperatura interna, sendo que o custo de energia para um avicultor é cerca de $30 \%$ da receita de uma criada, e de acordo com Turco, Ferreira e Furlan (2002), o consumo de energia elétrica em granjas de corte equivale a $0,16 \mathrm{kWh}$, para cada frango de corte alojado. Na Tabela 8 estão apresentados os valores de entalpia estimada nos horários de pico $(12: 00$ as $14: 00)$.

Tabela 8. Valores Estimados de Entalpia $(\mathrm{kJ} / \mathrm{kg})$ durantes as estações nas coberturas, exposições e nas inclinações de 10,20 e $50 \%$ Sul.

\begin{tabular}{|c|c|c|c|c|c|c|c|c|}
\hline & \multicolumn{2}{|l|}{ Verão } & \multicolumn{2}{|c|}{ Primavera } & \multicolumn{2}{|l|}{ Outono } & \multicolumn{2}{|c|}{ Inverno } \\
\hline & Norte & Sul & Norte & Sul & Norte & Sul & Norte & Sul \\
\hline Cerâmica & 129,7 & 124,0 & 107,3 & 102,6 & 93,0 & 85,1 & 95,9 & 84,3 \\
\hline Fibrocimento & 127,7 & 126,0 & 109,0 & 107,5 & 89,5 & 84,4 & 92,7 & 85,7 \\
\hline Aço Galvanizado & 134,0 & 135,2 & 114,3 & 115,1 & 97,5 & 95,7 & 99,7 & 96,6 \\
\hline \multicolumn{9}{|l|}{ Verão } \\
\hline & \multicolumn{2}{|c|}{ Cerâmica } & \multicolumn{3}{|c|}{ Fibrocimento } & \multicolumn{3}{|c|}{ Aço Galvanizado } \\
\hline $10 \% \mathrm{Sul}$ & \multicolumn{2}{|c|}{-} & \multicolumn{3}{|c|}{131,8} & \multicolumn{3}{|c|}{131,2} \\
\hline $20 \% \mathrm{Sul}$ & \multicolumn{2}{|c|}{128,3} & \multicolumn{3}{|c|}{ - } & \multicolumn{3}{|l|}{ - } \\
\hline $50 \% \mathrm{Sul}$ & \multicolumn{2}{|c|}{115,1} & \multicolumn{3}{|c|}{122,1} & \multicolumn{3}{|c|}{138,4} \\
\hline \multicolumn{9}{|l|}{ Primavera } \\
\hline & \multicolumn{2}{|c|}{ Cerâmica } & \multicolumn{3}{|c|}{ Fibrocimento } & \multicolumn{3}{|c|}{ Aço Galvanizado } \\
\hline $10 \% \mathrm{Sul}$ & \multicolumn{2}{|l|}{-} & \multicolumn{3}{|c|}{110,9} & \multicolumn{3}{|c|}{111,7} \\
\hline $20 \% \mathrm{Sul}$ & \multicolumn{2}{|c|}{104,6} & \multicolumn{3}{|c|}{-} & \multicolumn{3}{|c|}{-} \\
\hline $50 \% \mathrm{Sul}$ & \multicolumn{2}{|c|}{97,5} & \multicolumn{3}{|c|}{104,7} & \multicolumn{3}{|c|}{118,1} \\
\hline \multicolumn{9}{|l|}{ Outono } \\
\hline & \multicolumn{2}{|c|}{ Cerâmica } & & Fibrocime & & & alvani & \\
\hline $10 \% \mathrm{Sul}$ & - & & & 89,1 & & 95 & & \\
\hline $20 \% \mathrm{Sul}$ & 89,0 & & & - & & - & & \\
\hline $50 \% \mathrm{Sul}$ & 79,4 & & & 80,7 & & 94 & & \\
\hline Inverno & & & & & & & & \\
\hline & Cerâ & & & Fibrocime & & & alvani & \\
\hline $10 \% \mathrm{Sul}$ & - & & & 90,0 & & 96 & & \\
\hline $20 \% \mathrm{Sul}$ & 90,4 & & & - & & - & & \\
\hline $50 \% \mathrm{Sul}$ & 80,3 & & & 82,3 & & 94 & & \\
\hline
\end{tabular}

Fonte: Elaboração dos autores.

Entalpia é um índice que ultimamente tem sido usado para classificação do ambiente térmico em galpões de criação de frangos de corte. Os índices de conforto térmico são utilizados para quantificar e qualificar o desconforto térmico animal, que por sua vez, podem estar relacionados às respostas fisiológicas e desempenho produtivo das aves, sendo um método de avaliação indireto e relativamente prático. Ao observarmos os valores de entalpia estimada no interior dos modelos, percebemos que em todas as estações, mesmo no outono e inverno, os valores estão acima dos considerados ideais, pois segundo Barbosa Filho (2004), os limites de entalpia considerados ideais para as aves estão entre 64 e $70 \mathrm{~kJ} k g$ de $\operatorname{ar~seco}^{-1}$. 
Mas ao aumentarmos a inclinação e a maior área de exposição ao lado sul, podemos minimizar os valores de entalpia, como observado na Tabela 8. Neste contexto, as avaliações de respostas fisiológicas e desempenho produtivo como a entalpia, são formas de se avaliar a eficiência do sistema de criação e condições de bem-estar de frangos de corte, sendo as variáveis a elas relacionadas sofram interferência direta do ambiente interno de criação.

\section{Conclusões}

Com o aumento da inclinação da cobertura na exposição sul, houve um decréscimo do calor retido, da variação da temperatura e entalpia no interior do modelo, podendo propiciar menores temperaturas no interior de instalações zootécnicas, porém é necessária a realização de mais pesquisas para confirmar se esta diferença de temperatura é significativa do ponto de vista zootécnico.

\section{Agradecimentos}

Agradecemos a Fundação de Apoio a Pesquisa do Estado de São Paulo - FAPESP pelo financiamento deste projeto de pesquisa.

\section{Referencias}

ALMEIDA, M. G.; GARCIA, V.; MALDONADO, BRAGANÇA, L. A Influencia da temperatura e da radiaçao solar na capacidade de armazanamento térmico de elementos construtivos. Engenharia Civil, Portugal, v. 1, n. 5, p. 3-13, 1997.

BARBOSA FILHO, J. A. D. Avaliação do bem-estar de aves poedeiras em diferentes sistemas de produção e condições ambientais utilizando análises de imagens. 2004. Dissertação (Mestrado em Física do Ambiente Agrícola) - Escola Superior de Agricultura Luiz de Queiroz. Universidade de São Paulo, Piracicaba.

BOTTCHER, R. W.; WILLITS, D. H.; BAUGHMAN, G. R. Experimental analysis of wind ventilation of poultry buildings. Transactions of the ASAE, St. Joseph, v. 29, n. 2, p. 571-578, 1986.
CELIS, J. G.; JARA, J. C. Aplication del analisis dimensional para estimar la ventilacíon natural em galpones para aviários. Agro Ciência, Montecillo, v. 6, n. 1, p. 31-36, 1990.

COAN, R. M. Crescimento de grama-esmeralda em diferentes exposições e declividades. 2008. Tese (Doutorado em Engenharia Rural) - Faculdade de Ciências Agrárias e Veterinárias. Universidade Estadual Paulista, Jaboticabal.

CORDEIRO, M. B.; TINOCO, I. F. F.; SILVA, J. N.; VIGODERIS, R. B.; PINTO, F. A. C.; CECON, P. R. Conforto térmico e desempenho de pintos de corte submetidos a diferentes sistemas de aquecimento no período de inverno. Revista Brasileira de Zootecnia, Viçosa, v. 39, n. 1, p. 217-224, 2010.

FOREHLICH, D. P.; HELLICKSON, M. A.; YOUNG, H. G. Ridge vents effects on model ventilation characteristics. Transactions of the ASAE, St. Joseph, v. 18, n. 4, p. 690-693, 1975.

FURTADO, D. A.; AZEVEDO, P. V. de; TINOCO, I. F. F. Análise do conforto térmico em galpões avícolas com diferentes sistemas de acondicionamento. Revista Brasileira de Engenharia Agrícola e Ambiental, Campina Grande, v. 7, n. 3, p. 559-564, 2003.

HANN, L.; BOND, T. E.; KELLY, C. F. Use of models in thermal shades of livestock housing. Transactions of the $A S A E$, St. Joseph, v. 4, n. 1, p. 45-51, 1961

JÁCOME, I. M. T. D.; FURTADO, D. A.; LEAL, A. F.; SILVA, J. H. V.; MOURA, J. F. P. Avaliação de índices de conforto térmico de instalações para poedeiras no nordeste do Brasil. Revista Brasileira de Engenharia Agrícola Ambiental, Campina Grande, v. 11, n. 5, p. 527531, 2007.

MATIAS, I.; PATARRA, P. Genética: a invasão dos pintos avós e sua fórmula secreta. Revista Avicultura Industrial, n. 9, p. 34-60, 1995.

NÄÄS, I. A.; ROMANINI, C. E. B.; NEVES, D. P.; NASCIMENTO, G. R.; VERCELLINO, R. A. Broiler surface temperature distribution of 42 day old chickens. Scientia Agrícola, Piracicaba, v. 67, n. 5, p. 497-502, 2010.

OLIVEIRA, D. C. G.; PEREIRA, C. L.; MAC-LEAN, P. A. B.; LIMA, C. G.; JUNIOR, H. S. Avaliação do conforto térmico de galpões avícolas em escala reduzida com diferentes coberturas comerciais. In: CONGRESSO NACIONAL DOS ESTUDANTES DE ZOOTECNIA, 2009, Águas de Lindóia. Anais..... Águas de Lindóia: ZOOTEC, 2009. p. 1-4. 
OLIVEIRA, R. F. M.; DONZEL, J. L.; ABREU, M. L. T.; FERREIRA, R. A.; VAZ, R. G. M. V.; CELLA, P. $\mathrm{S}$. Efeitos da temperatura e da umidade relativa sobre $\mathrm{O}$ desempenho e o rendimento de cortes nobres de frangos de corte de 1 a 49 dias de idade. Revista Brasileira de Zootecnia, Viçosa, v. 35, n. 3, p. 797-803, 2006.

PARKER, B. F. Heat transmission caracteristics of sloped roofs exposed to solar radiation. Transactions of the ASAE, St. Joseph, v. 8, n. 1, p. 1-5, 1963.

SANTOS, P. A. dos; YANAGI JUNIOR, T.; TEIXEIRA, V. H. Ambiente térmico no interior de modelos de galpões avícolas em escala reduzida com ventilação natural e artificial dos telhados. Engenharia Agrícola, Jaboticabal, v. 25, n. 3, p. 575-584, 2005.

SARTOR, V.; BAETA, F. C.; LUZ, M. L.; ORLANDO, R. C. Sistemas de resfriamento evaporativo e o desempenho de frangos de corte. Scientia Agrícola, Piracicaba, v. 58, n. 1, p. 17-20, 2001.

SEVEGNANI, K. B.; GHELFI FILHO, H.; SILVA, I. J. O. da. Comparação de vários materiais de cobertura através de índices de conforto térmico. Scientia Agricola, Piracicaba, v. 51, n. 1, p. 1-7, 1994.
SILVA, R. B. T. R.; NAAS, I. A.; MOURA, D. J. Broiler and swine production: animal welfare legislation scenario. Scientia Agricola, Piracicaba, v. 66, n. 6, p. 713-720, 2009.

STATISTICAL ANALYSIS SYSTEM - SAS. SAS users guide: statistics. Cary: 2004. CD-ROM.

TINÔCO, I. F. F. Avicultura industrial: novos conceitos de materiais, concepções e técnicas construtivas disponíveis para galpões avícolas brasileiros. Revista Brasileira de Ciência Avícola, Campinas, v. 3, n. 1, p. 1-26, 2001.

TURCO, J. E. P. Modelo de crescimento da planta de soja para terrenos com diferentes exposições e declividades. 1997. Tese (Doutorado em Engenharia) - Escola de Engenharia de São Carlos. Universidade de São Paulo, São Carlos.

TURCO, J. E. P.; FERREIRA, L. F. S. A.; FURLAN, R. L. Consumo e custo de energia elétrica em equipamentos utilizados em galpão de frangos de corte. Revista Brasileira de Engenharia Agrícola Ambiental, Campina Grande, v. 6, n. 3, p. 519-522, 2002. 